\title{
A EMERGÊNCIA DO GÊNERO “RESUMO EXPANDIDO” SOB A ÓTICA DA TEORIA DA COMPLEXIDADE
}

\author{
Myrian Cristina Cardoso Costa \\ João da Silva Araújo Júnior**
}

RESUMO: Esta pesquisa objetiva relacionar alguns pressupostos da Teoria da Complexidade (LARSEN-FREEMAN, 2008; MORIN, 2011) com a noção de gêneros textuais - na perspectiva dialógica da linguagem de Bakhtin -, identificando, por meio dos elementos constitutivos dos gêneros - conteúdo, estilo e construção composicional -, em que condições o gênero textual secundário "resumo expandido" emerge na esfera acadêmica. Para tanto, realizamos uma breve discussão sobre os Gêneros Textuais e a Teoria da Complexidade, abordando algumas questões substanciais para a compreensão dessas duas abordagens teóricas como convergentes a partir da discussão dos seguintes tópicos: os gêneros na visão bakhtiniana; o gênero textual secundário "resumo expandido"; a emergência sob a ótica da complexidade; e a emergência do gênero "resumo expandido". Nesse sentido, entendemos que são as condições de uso e a necessidade de mudança que abrem espaço para que um gênero possa emergir, de modo que ao analisarmos o gênero "resumo expandido" sob a ótica do pensamento complexo, tanto a abertura como a plasticidade dos gêneros se tornam evidentes. Assim, percebemos que o tripé constituído por conteúdo, estilo e construção composicional evidencia a natureza multidimensional e complexa dos gêneros textuais, por meio da relação existente entre esses elementos e a esfera da comunicação na qual os gêneros se ancoram.

PALAVRAS-CHAVE: Complexidade; Gênero; Resumo expandido.

\section{Introdução}

Nas últimas décadas, tem sido corrente o esforço em compreender os fenômenos da linguagem à luz da Teoria da Complexidade. É o que se pode deduzir a partir de estudos

\footnotetext{
* Mestranda em Letras pela Universidade Federal do Maranhão (Ufma).

** Doutor em Linguística pela Universidade Federal do Ceará (UFC). Professor do Programa de Pós-Graduação em Letras da Universidade Federal do Maranhão (Ufma).
} 
como os de Leffa (2003); Larsen-Freeman (2008); Paiva e Nascimento (2011); Castilho (2011), entre outros. Nesses estudos, predomina, sobretudo, a compreensão de que fenômenos como língua, linguagem, discurso e texto devem ser compreendidos a partir do vínculo que estabelecem com o meio e com os sujeitos, e não como objetos isolados.

Nessa perspectiva, pensar a concepção bakhtiniana de linguagem pelo viés da complexidade não é uma tarefa tão difícil, uma vez que, para Mikhail Bakhtin, a linguagem não deve ser compreendida em si mesma e por si mesma, mas a partir de enunciados que se constituem com base nas relações de sentido que estabelecem entre si, ou seja, um enunciado não se concretiza isoladamente, mas a partir dos vínculos que estabelece com outros enunciados.

Segundo Faraco (2009), Bakhtin e o Círculo reconheceram a crescente percepção da complexa estratificação da linguagem e a questão da escolha estilística, que deixou de ser redutível ao espaço do sistema. Do mesmo modo, na perspectiva da Teoria da Complexidade, é exatamente essa concepção que permite um olhar a partir do qual os fenômenos podem ser observados como complexos.

Em se tratando de sistemas, uma de suas principais características, segundo Morin, é a abertura (MORIN, 2011). Essa noção parte da crítica ao sistema fechado, no qual os fenômenos se explicam por meio de uma única variável. Fazendo um paralelo, podemos afirmar que, nesse sentido, as teorias bakhtinianas reconhecem a abertura dos fenômenos linguísticos, imprimindo um nítido distanciamento em relação ao que propunha Saussure, que entendia a língua como um sistema fechado.

Vale ressaltar que nas teorias bakhtinianas se desconsidera qualquer pensamento segregador, visto que fica evidente nessas teorias que língua e contexto social se inter-relacionam e se interconectam. Assim, a visão arrolada, durante muito tempo, a uma abordagem cartesiana, na qual a língua é concebida como um sistema refratário às influências extralinguísticas, não se sustenta, uma vez que os estudiosos que compõem o Ciclo de Bakhtin entendem que a língua não só influencia o que está para além dela como também é influenciada. 
Como bem lembra Faraco (2009, p. 48), Medvedev, um dos principais representantes do Círculo, "considera inadequadas todas as abordagens positivistas e idealistas da criação ideológica". Nessa perspectiva, entendemos que a principal aproximação entre as teorias aqui mobilizadas centra-se no fato de a ideia de completude e de sistemas totalmente fechados e ordenados ser contestada. Nesse sentido, a visão dialógica da linguagem de Bakhtin e a Teoria da Complexidade convergem e se complementam.

Partindo desse princípio, nosso objetivo com este estudo é relacionar alguns pressupostos da Teoria da Complexidade (LARSEN-FREEMAN, 2008; MORIN, 2011) com a produção de gêneros textuais - na perspectiva dialógica da linguagem de Bakhtin -, identificando, por meio dos elementos constitutivos dos gêneros - conteúdo, estilo e construção composicional -, em que condições o gênero textual secundário "resumo expandido" emerge na esfera acadêmica.

Para tanto, realizamos uma breve discussão sobre os Gêneros Textuais e a Teoria da Complexidade, abordando algumas questões substanciais para a compreensão dessas abordagens teóricas como convergentes a partir da discussão dos seguintes tópicos: 1) Os gêneros e suas diferentes perspectivas; 2) Os gêneros na visão bakhtiniana; 2.1) O gênero textual secundário "resumo expandido"; 3) A emergência sob a ótica da complexidade; 4) A emergência do gênero "resumo expandido": conteúdo, estilo e construção composicional e 5) considerações.

Apresentaremos, como objeto de análise, exemplos de normas de submissão de resumos expandidos estabelecidas por comissões organizadoras de eventos acadêmicos de distintas áreas do conhecimento, selecionadas a partir do buscador do Google - plataforma que possui grande quantidade de dados e excelente capacidade de armazenamento de eventos que já ocorreram -, o que nos proporcionou uma ampla busca. Assim, selecionamos eventos ocorridos em 2014, 2015, 2016, 2017 e no ano vigente, sendo dois eventos por ano. 


\section{Os gêneros e suas diferentes perspectivas}

Nos últimos anos, as pesquisas centradas na noção de gênero textual vêm ganhando um espaço significativo nos estudos da linguagem. Esse interesse, segundo Antunes (2005), pode ser um reflexo da compreensão de que o conceito de gênero, em comparação, por exemplo, com a noção de texto, é bem mais concreto e, portanto, mais pertinente no que se refere ao estudo da linguagem.

O texto, na forma genérica com que é referido, ainda é percebido como um objeto teórico, uma categoria abstrata, uma referência geral a uma classe de coisas. No entanto, o texto que circula concretamente, quando se fala ou quando se escreve, é reconhecível socialmente como uma espécie modelar de interação verbal (a partir de particularidades de diferentes ordens); ou seja, o que circula concretamente, nos mais diferentes contextos sociais, é um gênero específico de texto. (ANTUNES, 2005, p. 53)

Muitas são, no entanto, as concepções de gêneros textuais que ancoram os estudos da linguagem e também amplas são as perspectivas sob as quais se abordam esses gêneros. Entre as diferentes perspectivas, vale destacar:

1. A perspectiva sociorretórica, cujo maior representante é John Swales (1990) e na qual o conceito de gênero se cerca de outros conceitos bastante significativos, tais como o de propósito comunicativo e o de comunidade discursiva. O primeiro é compreendido pelo autor como critério privilegiado de definição do gênero. O propósito comunicativo é o elemento que determina a estrutura esquemática do texto, seu conteúdo e seu estilo, sendo, portanto, a base do gênero. A comunidade discursiva, por sua vez, é compreendida como uma comunidade que tem convenções específicas e para a qual o discurso é parte constitutiva de seu comportamento social. 2. A perspectiva da nova retórica, cujos principais representantes são Miller (1994) e Bazerman (1994). Nessa perspectiva, o gênero é definido como "ação social".

3. A perspectiva da Escola de Sidney, a qual tem, ainda, Hasan (1989) e Martin (1992) entre seus expoentes, três signatários da teoria sistêmico-funcional, na qual 
a noção de gênero textual vem acompanhada do conceito de "registro", compreendido como situação imediata de realização do gênero.

4.A perspectiva sociointeracionista do chamado Círculo de Bakhtin, composto por intelectuais russos, entre os quais se destacam Bakhtin, Voloshinov e Medvedev, que se reuniam regularmente entre os anos de 1919 e 1974. Esses pensadores ressaltam o caráter histórico dos gêneros e os compreendem como enunciados relativamente estáveis e como elementos estabilizadores da comunicação humana.

5. A perspectiva do interacionismo sociodiscursivo (ISD) da Escola de Genebra, cujos maiores expoentes, Bronckart (1999), Schneuwly e Dolz (2004), desenvolvem estudos centrados na relação entre gêneros textuais e ensino. Esses dois últimos autores retomam os conceitos bakhtinianos e definem os gêneros textuais como "formas relativamente estáveis tomadas pelos enunciados em situações habituais, entidades culturais intermediárias que permitem estabilizar os elementos formais e rituais das práticas de linguagem" (SCHNEWULY; DOLZ, 2004, p. 74). Do interesse desses autores pela relação entre gênero e ensino é que se desenvolve a noção de "gênero escolar", o que representa uma contribuição significativa para a didática do ensino de línguas.

Das perspectivas acima mencionadas, a quarta - do Círculo de Bakhtin - é a mais relevante para o nosso estudo, e dela ressaltamos o caráter histórico e a relativa estabilidade dos gêneros textuais. Esses dois elementos nos parecem essenciais para a compreensão do gênero "resumo expandido", pois compreendemos que esse gênero deve ser entendido dentro de um determinado contexto histórico, qual seja, o surgimento e a popularização de novas modalidades de submissão de trabalhos em eventos de diferentes áreas do conhecimento. Essa perspectiva servirá, portanto, de referência para a análise que realizaremos das normas de submissão de resumos expandidos em eventos acadêmicos. 


\section{Os gêneros na visão bakhtiniana}

Uma das questões com a qual nos deparamos ao estudar o gênero na perspectiva do Círculo de Bakhtin se refere à flutuação terminológica existente nos escritos dos principais pensadores do grupo. É o que ocorre, por exemplo, com os conceitos de língua e discurso usados por Bakhtin ora como sinônimos, ora como realidades distintas.

Essa flutuação é, no dizer de Rodrigues (2005), uma estratégia bastante apreciada pelos escritores do Círculo. O gênero, nos escritos desse grupo, deve ser compreendido dentro do conjunto de outros conceitos nucleares, tais como: enunciado, que se confunde com o próprio conceito de gênero, e esfera de comunicação, também denominada esfera da atividade humana, que abordaremos mais adiante.

Em “Marxismo e Filosofia da Linguagem”, Bakhtin (1987) expõe de forma mais clara sua visão acerca da língua quando afirma que

[...] a verdadeira substância da língua não é constituída por um sistema abstrato de formas lingüísticas, nem pela enunciação monológica isolada, nem pelo ato psicofisiológico de sua produção, mas pelo fenômeno social da interação verbal realizada pela enunciação ou pelas enunciações (BAKHTIN, 1987, p. 123)

A partir dessa definição, depreendemos que o objeto central da teoria bakhtiniana é o enunciado, um evento comunicativo concreto que ocorre dentro de um determinado contexto comunicativo também concreto. São esses enunciados os quais Bakhtin denomina gêneros.

Para o autor, portanto, o conceito de gênero é concebido dentro de uma abordagem enunciativo-discursiva, com ênfase no processo de interação verbal e na noção de enunciado. Para Bakhtin (2000), a linguagem é um fenômeno social, histórico e ideológico. O gênero, por seu turno, é um enunciado relativamente estável desenvolvido dentro de uma determinada esfera da comunicação humana e gerado de acordo com as necessidades comunicativas de uma dada esfera da comunicação. Essas esferas compreendem os espaços interativos da produção discursiva, daí a possibilidade de se falar em discurso jurídico, discurso jornalístico, discurso religioso, entre outros. 
É importante asseverar que cada gênero é composto por características próprias da esfera de comunicação à qual pertence (BAKHTIN, 2000). Desta forma, o conteúdo, o estilo da linguagem e a construção composicional de cada gênero dependem, segundo o filósofo russo, da esfera da comunicação em que se realiza.

Cada uma dessas esferas - religiosa, científica, jornalística, acadêmica, etc. - elabora seus próprios tipos estáveis de enunciados. Uma dissertação de mestrado, por exemplo, pertence à esfera acadêmica e apresenta características próprias dessa esfera, tais como uma maior clareza na linguagem e um maior grau de objetividade; um salmo bíblico pertence, por sua vez, à esfera religiosa e apresenta características bem definidas no que concerne aos temas e aos propósitos comunicativos, como louvar, agradecer, etc. Portanto, “a utilização da língua efetua-se em forma de enunciados (orais e escritos) concretos e únicos que emanam dos integrantes duma ou doutra esfera da atividade humana" (BAKHTIN, 2000, p. 279).

Outro aspecto também relevante da concepção bakhtiniana, além de importante para a compreensão do resumo expandido como gênero e subsequente análise de sua estrutura e propósito, é a definição dos elementos constituintes de um gênero, os quais serão explicitados a seguir.

O primeiro elemento constitutivo de um gênero textual, segundo Bakhtin, é o conteúdo. Por conteúdo, compreendemos não apenas os temas recorrentes em determinado gênero, mas também as finalidades discursivas do enunciador. A temática de um gênero textual depende, é claro, da esfera da comunicação.

Um gênero da esfera religiosa e um da esfera jurídica, obviamente, têm, em geral, conteúdos temáticos diferentes devido ao contraste temático dessas esferas. Isso não significa, no entanto, que gêneros de diferentes esferas não possam abordar temas semelhantes, ainda que sob óticas diversas.

Sobre a noção de conteúdo temático na concepção bakhtiniana, Rodrigues (2005) argumenta que todo gênero tem um conteúdo temático determinado: seu objetivo e sua 
finalidade discursiva, o que faz com que gêneros com conteúdos temáticos afins se diferenciem. Por exemplo, um romance literário que trate de um assassinato e uma notícia jornalística que aborde o mesmo tema, entre outras coisas, vão se diferenciar pela finalidade discursiva do enunciador/escritor, que, no primeiro caso, é essencialmente gerar prazer no leitor e, no segundo, mantê-lo informado.

O segundo elemento constitutivo do gênero é o que Bakhtin denomina estilo, compreendido aqui como a seleção de recursos lexicais fraseológicos e gramaticais em um determinado gênero. Bakhtin (2000) chama a atenção para o fato de que alguns gêneros tornam mais possível a expressão do estilo individual de quem o produz; é o caso, segundo o autor, dos gêneros da esfera literária, como o romance e o poema, por exemplo, onde o estilo individual faz parte dos propósitos dos próprios gêneros. O mesmo não ocorre com os gêneros de natureza mais padronizada, como os documentos oficiais da esfera jurídica, por exemplo.

O terceiro elemento da perspectiva bakhtiniana é a construção composicional, ou seja, os padrões de organização discursiva de um dado gênero, o que faz com que apenas visualmente, sem que seja necessário adentar no conteúdo, diferenciemos um gênero de outro. Uma carta - gênero composto tradicionalmente de: local, data, saudação, corpo do texto, despedida e assinatura -, por exemplo, tem a construção composicional diferente da de um chat na internet, gênero construído basicamente por uma sequência dialogal (ARAÚJO, 2007).

No Brasil, assim como em outros países, as ideias do Círculo de Bakhtin acerca de gênero, somadas a conceitos advindos de outras perspectivas, têm influenciado pesquisas com os mais variados propósitos, seja no âmbito teórico, seja no prático. Assim, destacamos aplicações da visão bakhtiniana nas seguintes pesquisas: Antunes (2005), sobre o gênero aviso; Paiva (2005), sobre a definição e estrutura do gênero e-mail; Xavier; Santos (2005), a respeito do gênero Fórum eletrônico (FE); Caiado (2007), acerca da influência da escrita no meio digital, em especial a do gênero Weblog, na escrita escolar, entre tantas outras. 
A noção de gênero enquanto fenômeno atrelado às necessidades comunicativas da sociedade, como defende o Círculo de Bakhtin, é basilar para o nosso estudo, pois compreendemos que o gênero resumo expandido emerge dentro de uma determinada esfera da comunicação: a acadêmica.

É nesse ponto também que as teorias arroladas neste estudo convergem, quando fica evidente - ainda que cada gênero possua uma estrutura composicional muito particular - que os gêneros são abertos, uma vez que as necessidades comunicativas da sociedade são contempladas, o que permite que gêneros como o supracitado possam ser explorados.

Portanto, o resumo expandido não surge sem que haja uma justificativa para a sua existência; ele decorre de outros gêneros já existentes e se desenvolve em conformidade com os avanços e necessidades que o âmbito acadêmico passa a ter, configurando novas formas de escrever um trabalho acadêmico, com uma estrutura diferente, ainda que baseada em outras mais tradicionais.

\section{O gênero textual secundário "resumo expandido"}

Entendendo o resumo expandido como um gênero secundário, a partir da distinção que Bakhtin (2003 apud RODRIGUES, 2005) estabelece entre dois grupos de gêneros e que, segundo Rodrigues (2005, p. 169), se trata de uma diferenciação histórica, assentada na concepção socioideológica da linguagem, fica evidente que o olhar lançado sobre os gêneros, neste trabalho, se justifica mais uma vez pelos pontos de convergência que a Teoria da Complexidade e a perspectiva bakhtiniana têm acerca dos fenômenos.

Para Bakhtin, a compreensão da linguagem como fenômeno que sofre influência do meio social é basilar no entendimento das diferenças entre os dois grupos de gêneros. Além disso, o autor afirma também que

[...] os gêneros primários se constituem na comunicação discursiva imediata, no âmbito da ideologia do cotidiano. Os gêneros secundários surgem nas condições da comunicação cultural mais "complexa", no âmbito das ideologias formalizadas e especializadas, que, uma vez constituídas, "medeiam" as interações sociais. (BAKHTIN, 2003 apud RODRIGUES, 2005, p. 169) 
O autor também salienta que muitos gêneros secundários, em seu processo de formação, absorvem e reelaboram diversos gêneros primários, visto que "muitos gêneros nascem do hibridismo de outros gêneros” (RODRIGUES, 2005, p. 169). Esse é o caso do gênero resumo expandido, que surge, ou melhor, emerge a partir de outros gêneros e da necessidade comunicativa da esfera acadêmica.

Embora considerado por muitos pesquisadores como um gênero inadequado, por vezes pitoresco, uma vez que não se encaixa na estrutura de artigo, tampouco na de um resumo simples ou tradicional - embora a maioria dos participantes de eventos acadêmicos estejam acostumados a lidar -, o resumo expandido se apresenta como uma modalidade de submissão de trabalhos cada vez mais recorrente nas mais diferentes áreas do conhecimento, ainda que suscite estranhamento, ou mesmo repúdio, em um bom número de pesquisadores.

Entre as razões pelas quais alguns pesquisadores contestam o gênero emergente, está o fato de que, para a Academia, em termos de produção, a publicação em Anais de eventos - sobretudo quando se trata de um resumo, seja ele simples ou expandido - é, por vezes, encarada como sendo de pouca relevância e impacto para o Currículo Lattes, por exemplo.

Esse fato, embora não represente uma novidade, serve para exemplificar o caráter dinâmico que as modalidades de submissão de trabalhos em eventos apresentam, uma vez que, mesmo seguindo um padrão predeterminado, novas categorias surgem, como ocorreu com o resumo expandido. Vale ressaltar que, em meio a um período de mudanças, principalmente na última década, esse gênero foi adaptado para atender a algumas necessidades que as demais modalidades não suprem, ou que se encaixam melhor no modelo de evento que se pretende realizar. Nesse sentido, o processo de intercalação de gêneros é um dos fatores que possibilita observar a plasticidade dos gêneros (RODRIGUES, 2005, p. 169).

É verdade que isso implica em outras reflexões, como o fato de tornar questionável o rigor teórico e metodológico com o qual um determinado gênero é realizado, assim como implica também no entendimento de que a pesquisa foi realizada de modo mais superficial. 
Em contrapartida, tal posicionamento pode ser facilmente contestado por quem não concorda com essa linha de raciocínio ou simplesmente visualiza os benefícios dessa modalidade de submissão. De mais a mais, as condições em que esses trabalhos são submetidos - para publicação ou como critério de seleção de artigos completos a serem publicados também são consideradas, entretanto, esse não é o foco deste estudo e por isso não nos dedicaremos a discorrer mais sobre esse aspecto.

Destarte, com este artigo pretendemos discorrer sobre como os pressupostos da Teoria da Complexidade se relacionam à produção e à circulação de um novo gênero na esfera acadêmica. Essa reflexão - considerando o paralelo que se pode estabelecer entre essas ideias - nos parece ser uma tarefa enriquecedora, pois, com base nos postulados do pensamento complexo, qualquer certeza é, na verdade, um mito, uma vez que é pretencioso afirmar algo com exatidão ante um mar de incertezas que nos cerca. Assim, discutir, refletir e descobrir são atividades de exercício do pensamento e de propagação de conhecimento.

\section{A emergência sob a ótica da complexidade}

Um paradigma representa um conjunto de princípios teóricos e epistemológicos compartilhados por uma comunidade científica (KUHN, 2003) e, com o paradigma da complexidade, não é diferente. Este representa uma síntese de diferentes abordagens científicas que possuem a noção de complexidade presente em seus modelos epistemológicos.

Morin, na obra Introdução ao pensamento complexo, quando trata do sujeito e do objeto, afirma que "a ciência ocidental fundamentou-se na eliminação positivista do sujeito a partir da ideia de que os objetos, existindo independentemente do sujeito, podiam ser observados e explicados enquanto tais" (MORIN, 2011, p. 39).

Em linhas gerais, podemos afirmar que o paradigma da complexidade surge a partir da necessidade de que as velhas ideias dessem lugar às novas. Embora essa simples proposição diga muito a respeito do que o paradigma postula, uma vez que este objetiva romper com a ciência de caráter positivista, pautada na redução, na simplificação e na causalidade 
fortemente vigente no modo de fazer ciência até o século XIX, é importante ressaltar também que, para além desse rompimento, o paradigma visa diferenciar sem segregar, e separar sem reduzir.

Na obra Educar na era planetária: o pensamento complexo como método de aprendizagem pelo erro e incerteza bumana, Morin e Motta deixam claro que o pensamento complexo rompe com o modelo científico radicado na redução, na simplificação, nas relações diretas de causa e efeito ao afirmarem que "esse tipo de redução, inteiramente necessária, torna-se cretinizante e destrutiva quando se acredita como suficiente, ou seja, quando pretende explicar tudo" (MORIN et al, 2003, p. 45).

Embora o pensamento complexo represente uma revolução no modo de fazer ciência, imprimindo um corte epistemológico com relação ao modelo vigente no século XIX, é importante considerar que pensar segundo o paradigma da complexidade é tentar dar conta de questões ignoradas, até então, e, por isso, polarizadas ou descartadas, consequentemente.

Como afirma Morin et al (2003, p. 56), o pensamento complexo, no entanto, não é sinônimo "de uma ode ao vale-tudo nem ao ceticismo generalizado, mas de uma luta contra o absolutismo e o dogmatismo disfarçados de verdadeiro saber". Dito de outra forma, o pensamento complexo não é sinônimo de tudo, ou qualquer coisa, mas uma resposta à simplificação que fracassou, na tentativa de explicar os fenômenos sociais e culturais, bem como os linguísticos, a partir de uma única variável. Os autores deixam claro que "um pensamento complexo nunca é um pensamento completo" (MORIN et al, 2003, p. 54). A ideia de completude, na verdade, é um dos mitos que se constroem em torno do que passamos a entender como paradigma da complexidade.

Morin conceitua complexidade mencionando algumas das principais características que são substanciais para o entendimento de tal pensamento:

O que é a complexidade? À primeira vista é um fenômeno quantitativo, a extrema quantidade de interações e de interferências entre um número muito grande de unidades. De fato todo sistema auto-organizador (vivo), mesmo o mais simples, combina um número muito 
grande de unidades da ordem de bilhões, seja de moléculas numa célula, seja de células no organismo [...] Mas a complexidade não compreende apenas quantidades de unidade e interações que desafiam nossas possibilidades de cálculo: ela compreende também incertezas, indeterminações, fenômenos aleatórios. A complexidade num certo sentido sempre tem relação com o acaso. (MORIN, 2011, p. 35)

Embora a ideia de incerteza seja também central na discussão sobre complexidade, esta não traduz todo o pensamento complexo, pois embora este seja permeado por incertezas, ele é sobretudo entendido como algo que não é completo. Ademais, a complexidade não tem a intenção de excluir, por isso também se fala em incerteza, uma vez que a relação de causa e efeito não é central e direta, ou seja, nada pode ser previsível a ponto de garantir certeza total, pois "a complexidade não é nem a simplificação colocada às avessas, nem a eliminação do simples: a complexidade é a união da simplificação e da complexidade" (MORIN et al, 2003, p. 56).

Essa união entre o simples e o complexo é um dos fatores que contribuem para o surgimento de novos padrões no comportamento dos agentes dentro do sistema e no comportamento do próprio sistema, dado que ao interagirem de maneira aparentemente aleatória e não-linear, os agentes de um sistema aberto promovem a emergência de novos padrões de comportamento dentro do sistema como um todo. "O pensamento complexo deve realizar a rotação da parte para o todo, do todo para a parte” (MORIN et al, 2003, p. 57) e, como discutimos até o momento, é assim que o gênero resumo expandido se descortina.

A emergência é a propriedade relativa aos novos padrões que surgem das interações entre os diversos agentes de um sistema. O resumo expandido, por exemplo, é um gênero secundário e se constitui a partir de outros gêneros. Nesse sentido, segundo Faraco, "Bakhtin articula uma compreensão dos gêneros que combina estabilidade e mudança; reiteração e abertura para o novo" (FARACO, 2009, p. 128).

Em síntese, entre as várias características do pensamento complexo, destacam-se as seguintes: i) "a certeza generalizada é um mito" (MORIN et al, 2003, p. 53), uma vez que 
não constitui objetivo do paradigma da complexidade estabelecer verdades absolutas; ii) "um pensamento complexo nunca é um pensamento completo", e, por isso, contesta a ideia de completude e dos sistemas fechados (MORIN et al, 2003, p. 54); iii) o pensamento complexo não “desprez[a] o simples, critica a simplificação” (MORIN et al, 2003, p. 56), e iv) o pensamento complexo "não exclui a linearidade" (MORIN et al, 2003, p. 58), embora seja não-linear.

Embora essa breve discussão não contemple todas as contribuições que o pensamento complexo tem dado desde o seu surgimento, acreditamos que, a partir de algumas das características do pensamento complexo apresentadas aqui, seja possível visualizar o gênero resumo expandido como um gênero emergente.

\section{A emergência do gênero resumo expandido: conteúdo, estilo e construção compo- sicional}

Como discutimos anteriormente, os gêneros possuem características próprias da esfera de comunicação à qual pertencem (BAKHTIN, 2000). No caso do resumo expandido, podemos afirmar que este se delineia a partir de seu conteúdo, do seu estilo e de sua construção composicional no âmbito acadêmico. Esse gênero emergente estabelece relação direta com a esfera da comunicação na qual está ancorado e, em decorrência disso, os seus elementos constitutivos se delineiam em conformidade com o propósito que determinada comunidade estabelece.

Nessa discussão, é evidente que os elementos constitutivos do gênero evidenciam a natureza complexa que este possui, uma vez que cada um dos elementos estabelece relação direta com a esfera da comunicação, que é dinâmica, não linear e aberta a mudanças. Em seus estudos, Faraco afirma que Bakhtin "lembra que há gêneros bastante estandardizados como certos tipos de documentos oficiais, contudo, mesmo estes admitem mudanças, ou seja, estão abertos à adequação, às condições concretas de uso" (FARACO, 2009, p. 128). Portanto, são as condições de uso e a necessidade de mudança que abrem espaço 
para que um gênero possa emergir. E quando lançamos nosso olhar com viés no pensamento complexo direcionado para o resumo expandido, tanto a abertura como a plasticidade dos gêneros se tornam inquestionáveis.

No que diz respeito ao conteúdo temático na concepção bakhtiniana, Rodrigues (2005) afirma que todo gênero tem um conteúdo temático determinado e esse é um dos fatores que nos ajudam a diferenciar um gênero de outro, ainda que estes sejam próximos ou produtos de intercalação entre gêneros. O resumo expandido, por exemplo, se diferencia do resumo simples, embora os conteúdos temáticos sejam, eventualmente, afins.

Comumente apresentado em eventos como porta de entrada para o recebimento de artigo, o resumo simples é mais sintético e objetivo; o resumo expandido, não, pois contém informações mais detalhadas que não são contempladas no resumo simples por não configurar um interesse desse tipo de produção, além do fato de que o escopo de cada um é diferente e, consequentemente, também os objetivos. Em geral, o resumo expandido é o próprio documento de entrada (para avaliação e posterior publicação), ao contrário do resumo simples. Em todas as dez normas analisadas neste trabalho, por exemplo, nenhuma traz, em suas recomendações ao participante, a ideia de posterior submissão de artigo, já que este se configura como um outro gênero que não é privilegiado dentro dessa esfera comunicacional que se constrói com o uso do gênero resumo expandido.

No que diz respeito ao estilo, entendido a partir do que nos diz Bakhtin, este tem a ver com a seleção de recursos lexicais, fraseológicos e gramaticais em um determinado gênero. O resumo expandido, vale destacar, também tem seu próprio estilo e, inclusive, obedece à norma culta da Língua Portuguesa. Nas tabelas a seguir, é possível visualizar melhor algumas informações pertinentes às normas de submissão utilizadas em nossa breve análise. A primeira delas diz respeito a alguns dados gerais e nos mostram dez eventos de diferentes áreas do conhecimento que usam o resumo expandido como uma modalidade de submissão em seus respectivos eventos. 
Tabela 1 - Eventos acadêmicos com modalidade de submissão de resumo expandido

\begin{tabular}{|c|c|c|c|c|}
\hline $\mathbf{N}^{\circ}$ & Nome do evento & Porte & $\begin{array}{l}\text { Área do conhecimento } \\
\text { /Temática }\end{array}$ & Ano \\
\hline 1 & $\begin{array}{l}\text { V CONGRESSO DE INICIA- } \\
\text { ÇÃO CIENTÍFICA DO CEN- } \\
\text { TRO UNIVERSITÁRIO DE } \\
\text { ITAJUBÁ-FEPI }\end{array}$ & Local & $\begin{array}{l}\text { Ciências Agrárias, Biológi- } \\
\text { cas, Exatas e da Terra, Hu- } \\
\text { manas, Linguística, Letras e } \\
\text { Artes, Saúde e Sociais Apli- } \\
\text { cadas. }\end{array}$ & 2014 \\
\hline 2 & $\begin{array}{l}6^{\circ} . \text { SEMINÁRIO NACIONAL } \\
\text { E } 2^{\circ} . \text { SEMINÁRIO DE DIREI- } \\
\text { TOS HUMANOS }\end{array}$ & Nacional & $\begin{array}{l}\text { Políticas Sociais e Direitos } \\
\text { Humanos. }\end{array}$ & 2014 \\
\hline 3 & $\begin{array}{l}3^{\circ} \text { CONGRESSO INTERNA- } \\
\text { CIONAL EM SAÚDE: ATEN- } \\
\text { ÇÃO INTEGRAL À SAÚDE }\end{array}$ & Internacional & Saúde. & 2015 \\
\hline 4 & $\begin{array}{l}\text { I WORKSHOP INTERNACI- } \\
\text { ONAL POTENCIAL BIOTEC- } \\
\text { NOLÓGICO DE ESPÉCIES } \\
\text { VEGETAIS E DE MICROOR- } \\
\text { GANISMOS }\end{array}$ & Internacional & Biotecnologia. & 2015 \\
\hline 5 & $\begin{array}{l}\text { XV ENCONTRO DO PRO- } \\
\text { GRAMA DE INICIAÇÃO CI- } \\
\text { ENTÍFICA/UFRR }\end{array}$ & Local & $\begin{array}{l}\text { Ciências Agrárias, Biológi- } \\
\text { cas, Exatas e da Terra, Hu- } \\
\text { manas, Linguística, Letras e } \\
\text { Artes, Saúde e Sociais Apli- } \\
\text { cadas. }\end{array}$ & 2016 \\
\hline 6 & $\begin{array}{l}\text { IV SEMANA JURÍDICA DA } \\
\text { FACULDADE GUANAMBI }\end{array}$ & Local & Direito. & 2016 \\
\hline 7 & $\begin{array}{l}\text { XVI ENCONTRO DO PRO- } \\
\text { GRAMA DE INICIAÇÃO CI- } \\
\text { ENTÍFICA/UFRR }\end{array}$ & Local & $\begin{array}{l}\text { Ciências Agrárias, Biológi- } \\
\text { cas, Exatas e da Terra, Hu- } \\
\text { manas, Linguística, Letras e } \\
\text { Artes, Saúde e Sociais Apli- } \\
\text { cadas. }\end{array}$ & 2017 \\
\hline 8 & $\begin{array}{l}8^{\circ} \text { CONGRESSO DE INOVA- } \\
\text { ÇÃO, CIÊNCIA E TECNOLO- } \\
\text { GIA DO IFSP }\end{array}$ & Local & $\begin{array}{l}\text { Biológicas, Exatas e da } \\
\text { Terra, Humanas, Linguís- } \\
\text { tica, Letras e Artes, Saúde e } \\
\text { Sociais Aplicadas. }\end{array}$ & 2017 \\
\hline 9 & $\begin{array}{l}\text { VII CICFE - OUTUBRO DE } \\
2018 \text { E VII CONGRESSO DE } \\
\text { INICIAÇÃO CIENTÍFICA DA } \\
\text { FUNDAÇÃO DA EDUCACI- } \\
\text { ONAL DE ITUVERAVA/FE }\end{array}$ & Local & $\begin{array}{l}\text { Biológicas, Exatas e da } \\
\text { Terra, Humanas, Linguís- } \\
\text { tica, Letras e Artes, Saúde e } \\
\text { Sociais Aplicadas. }\end{array}$ & 2018 \\
\hline 10 & $\begin{array}{l}\text { II SEMINÁRIO INTERNACI- } \\
\text { ONAL DE PESQUISA EM MI- } \\
\text { DIATIZAÇÃO E PROCESSOS } \\
\text { SOCIAIS }\end{array}$ & Internacional & $\begin{array}{l}\text { Midiatização e Processos } \\
\text { Sociais }\end{array}$ & 2018 \\
\hline
\end{tabular}

Fonte: Produção dos próprios autores. 
Como vimos, a tabela demonstra dez trabalhos, sendo dois de cada ano $(2014,2015$, 2016, 2017 e 2018). Esse quadro é muito representativo não apenas pelos números que traz, mas também por aquilo que explicita. Na discussão promovida até o momento, discorremos sobre o caráter dinâmico e plástico dos gêneros e também o fato de as normas para submissão de resumos expandidos serem contempladas em eventos a nível local, nacional e internacional, o que evidencia a emergência desse gênero e sua abertura a adequações e a condições concretas de uso, como mencionamos anteriormente.

No que concerne à estrutura composicional - elemento de maior interesse para esta breve análise, dado que esta se pauta apenas nas verificações das normas de submissão dos eventos -, é importante destacar sua relevância, pois através dela é que um gênero se diferencia de outro. $\mathrm{Na}$ tabela 2, é possível notar que, embora a estrutura do resumo expandido siga, de modo muito semelhante, as normas preestabelecidas para a elaboração dos resumos tradicionais, a principal diferença entre esses gêneros está no tamanho, ou seja, no número de caracteres utilizados para que determinada pesquisa seja explicitada. Esse fator, que a princípio pode parecer algo sem muita significância, é, na verdade, o fator diferencial não apenas pelos números e dados visualizados em detalhes (ver tabela abaixo), mas principalmente por aquilo que estes representam enquanto estrutura composicional.

Tabela 2 - Construção composicional

\begin{tabular}{|c|c|c|c|c|c|}
\hline $\mathbf{N}^{\mathbf{o}}$ & Ano & $\begin{array}{c}\text { Número de } \\
\text { páginas/ } \\
\text { palavras/carac- } \\
\text { teres }\end{array}$ & Estrutura & $\begin{array}{l}\text { Solicita } \\
\text { normas } \\
\text { segundo } \\
\text { a ABNT }\end{array}$ & $\begin{array}{c}\text { Fonte e } \\
\text { Tamanho }\end{array}$ \\
\hline 1 & 2014 & $\begin{array}{l}\text { No mínimo, duas } \\
\text { e, no máximo, } \\
\text { quatro. }\end{array}$ & $\begin{array}{l}\text { Título; autores; condição e ins- } \\
\text { tituição; palavras-chave; intro- } \\
\text { dução; materiais e métodos; } \\
\text { discussão e resultados; referên- } \\
\text { cias. }\end{array}$ & $\mathrm{X}$ & Arial, 12. \\
\hline 2 & 2014 & $\begin{array}{l}\text { Entre qua- } \\
\text { tro e cinco pági- } \\
\text { nas. }\end{array}$ & $\begin{array}{l}\text { Resumo (com até } 200 \text { pala- } \\
\text { vras); palavras-chave (de três a } \\
\text { quatro separadas por ponto e } \\
\text { vírgula); introdução (com deli- } \\
\text { mitação do tema); objetivos; }\end{array}$ & $\mathrm{X}$ & $\begin{array}{c}\text { Times } \\
\text { New } \\
\text { Roman, } \\
12 .\end{array}$ \\
\hline
\end{tabular}




\begin{tabular}{|c|c|c|c|c|c|}
\hline & & & $\begin{array}{l}\text { procedimentos metodológi- } \\
\text { cos (incluindo aspectos éti- } \\
\text { cos); resultados; conclusões e } \\
\text { referências. }\end{array}$ & & \\
\hline 3 & 2015 & $\begin{array}{l}\text { No mínimo, } 6 \text { mil } \\
\text { caracteres e, no } \\
\text { máximo, } 13 \text { mil } \\
\text { caracteres. }\end{array}$ & $\begin{array}{l}\text { Resumo; palavras-chave; intro- } \\
\text { dução; metodologia; resultados } \\
\text { e discussão; conclusões; agra- } \\
\text { decimentos; referências biblio- } \\
\text { gráficas. }\end{array}$ & $\mathrm{X}$ & Arial, 12. \\
\hline 4 & 2015 & $\begin{array}{l}\text { No mínimo, } \\
3.000 \text { e, no má- } \\
\text { ximo, } 5.000 \text { pala- } \\
\text { vras (sem contar } \\
\text { os caracteres), no } \\
\text { máximo, } 10 \text { (dez) } \\
\text { páginas. }\end{array}$ & $\begin{array}{l}\text { Introdução; metodologia, ma- } \\
\text { teriais; resultados e discussão; } \\
\text { conclusões; palavras-chave; } \\
\text { agradecimento; referências. }\end{array}$ & $\mathrm{X}$ & Arial, 12. \\
\hline 5 & 2016 & $\begin{array}{l}\text { No máximo qua- } \\
\text { tro páginas. }\end{array}$ & $\begin{array}{l}\text { Introdução; material e méto- } \\
\text { dos; resultados e discussão; } \\
\text { conclusões; agradecimentos } \\
\text { (opcional) e referências. }\end{array}$ & $\mathrm{X}$ & $\begin{array}{l}\text { Times } \\
\text { New } \\
\text { Roman, } \\
12 . \\
\end{array}$ \\
\hline 6 & 2016 & $\begin{array}{l}\text { No mínimo } 8 \text { mil, } \\
\text { no máximo } 20 \\
\text { mil caracteres e, } \\
\text { no máximo, } 5 \\
\text { (cinco) páginas. }\end{array}$ & $\begin{array}{l}\text { Introdução; metodologia; ma- } \\
\text { teriais; resultados e discussão; } \\
\text { conclusões; palavras-chave; } \\
\text { agradecimento; referências. }\end{array}$ & $\mathrm{X}$ & Arial, 12 \\
\hline 7 & 2017 & $\begin{array}{l}\text { No máximo, qua- } \\
\text { tro páginas. }\end{array}$ & $\begin{array}{l}\text { Introdução; material e méto- } \\
\text { dos; resultados e discussão; } \\
\text { conclusões; agradecimentos } \\
\text { (opcional) e referências. }\end{array}$ & $\mathrm{X}$ & $\begin{array}{l}\text { Times } \\
\text { New } \\
\text { Roman, } \\
12 . \\
\end{array}$ \\
\hline 8 & 2017 & $\begin{array}{l}\text { No mínimo, duas } \\
\text { e, no máximo, } \\
\text { três páginas. }\end{array}$ & $\begin{array}{l}\text { Título (centralizado); nome } \\
\text { dos autores; identificação dos } \\
\text { autores; identificação do } \\
\text { evento (centralizado); resumo } \\
\text { (máximo de } 200 \text { palavras); pa- } \\
\text { lavras-chave; título em inglês; } \\
\text { abstract; keywords (máximo de } \\
\text { seis); introdução (máximo de } \\
20 \text { linhas); material e métodos; } \\
\text { resultados e discussão; conclu- } \\
\text { sões; agradecimentos e refe- } \\
\text { rências. }\end{array}$ & $\mathrm{X}$ & $\begin{array}{l}\text { Tim } \\
\text { es New } \\
\text { Roman, } \\
11 .\end{array}$ \\
\hline 9 & 2018 & $\begin{array}{l}\text { No máximo } 3 \text { pá- } \\
\text { ginas. }\end{array}$ & $\begin{array}{l}\text { Título (centralizado); nome } \\
\text { dos autores (centralizados, } \\
\text { máximo quatro autores por } \\
\text { trabalho); afiliação dos autores; }\end{array}$ & $\mathrm{X}$ & $\begin{array}{l}\text { Times } \\
\text { New } \\
\text { Roman, } \\
\text { 11, para } \\
\text { nome dos }\end{array}$ \\
\hline
\end{tabular}




\begin{tabular}{|c|c|c|c|c|}
\hline & & $\begin{array}{l}\text { identificação do evento (cen- } \\
\text { tralizado); resumo (máximo de } \\
200 \text { palavras); palavras-chave } \\
\text { (máximo de seis separadas } \\
\text { por ponto e vírgula); título } \\
\text { em Inglês, abstract, keywords } \\
\text { (máximo de seis); introdução } \\
\text { (máximo de } 20 \text { linhas); mate- } \\
\text { rial e métodos; resultados e } \\
\text { discussão, Conclusões; agra- } \\
\text { decimentos e referências. }\end{array}$ & & $\begin{array}{c}\text { autores, } \\
\text { texto e } \\
\text { identifica- } \\
\text { ção do } \\
\text { evento, e } \\
\text { tamanho } 9 \\
\text { para iden- } \\
\text { tificação } \\
\text { dos auto- } \\
\text { res. }\end{array}$ \\
\hline 10 & $\begin{array}{ll}2018 & \text { Entre } 1500 \text { e } \\
& 2000 \text { palavras. }\end{array}$ & $\begin{array}{l}\text { Título do texto; corpo do } \\
\text { texto; citações; notas de ro- } \\
\text { dapé; referências bibliográfi- } \\
\text { cas. }\end{array}$ & $X$ & $\begin{array}{c}\text { Times } \\
\text { New } \\
\text { Roman, } \\
\text { 16, ne- } \\
\text { grito, es- } \\
\text { paço en- } \\
\text { trelinhas } \\
\text { simples } \\
(1,0) \text {, cen- } \\
\text { tralizado. }\end{array}$ \\
\hline
\end{tabular}

Fonte: Produção dos próprios autores.

Em geral, o resumo tradicional permite até 500 palavras ou 1500 caracteres, já o resumo expandido varia entre 2 e 5 páginas, podendo chegar a até 10, no total, em alguns casos isolados. Já o número de caracteres, varia de 3 mil a 21 mil.

A construção composicional, ou seja, os padrões de organização discursiva de um dado gênero, possibilitam que apenas visualmente, sem necessariamente adentar no conteúdo, diferenciemos um gênero de outro, além de conduzir os participantes a submeterem um resumo expandido ou um resumo simples nos eventos acadêmicos dos quais participam.

\section{Considerações finais}

Neste trabalho percebemos que o tripé (conteúdo, estilo e construção composicional) aqui apresentado e analisado, ainda que de modo breve, confirma a natureza multidimensional e complexa dos gêneros textuais, por meio da relação existente entre esses elementos e a esfera da comunicação na qual os gêneros se ancoram. Podemos observar que 
ambos os elementos se comportam de forma não linear, uma vez que os gêneros são dinâmicos e plásticos, como é o caso do resumo expandido.

Evidenciamos também alguns pontos de convergência entre a teoria bakhtiniana e a Teoria da Complexidade. Sem adentrar na discussão sobre o fato de o resumo expandido constituir ou não um bom gênero para compor uma modalidade de submissão na esfera acadêmica, identificamos que o pensamento complexo muito tem a ver com a noção de estabilidade e mudança apontada por Bakhtin no que diz respeito aos gêneros textuais.

A partir do que postula a Teoria da Complexidade, entendemos que a natureza aberta dos sistemas permitiu a emergência de um novo gênero textual na esfera acadêmica nos últimos anos: o resumo expandido. Todavia, como discutimos no decorrer do trabalho, tal fato não significa que tal emergência fosse totalmente previsível.

A esse respeito, é interessante observar que, no tocante aos eventos da área de Letras e Linguística, especificamente no que concerne aos últimos eventos divulgados no site da ANPOLL ${ }^{31}$, nenhum deles contempla a modalidade de resumo expandido em seus congressos e encontros.

Tal fato revela - não apenas por se tratar da área de Letras, pois essa prática se repete em algumas outras áreas, principalmente quando se trata de eventos de maior porte, sobretudo os internacionais - que a recorrência do uso desse gênero se dá em condições muito específicas e não pode ser generalizada.

Diversos são os fatores que interferem diretamente na escolha do gênero como modalidade de inscrição, como, por exemplo, as determinações e posicionamentos da comissão científica que compõe o evento, a concepção de gêneros que cada uma delas possui, o entendimento desse gênero como uma escolha capaz de suprir necessidades de discussão das pesquisas em questão, os objetivos e o público-alvo, entre vários outros fatores que poderiam ser elencados aqui e que, por essa razão, deixam um convite para novas reflexões.

\footnotetext{
${ }^{31}$ Fonte: site da ANPOLL - Associação Nacional de Pós-graduação e Pesquisa em Letras e Linguística. Disponível em: http://anpoll.org.br/portal/pt/category/eventos/\#titulo. Acesso em 10/12/2018.
} 


\section{LA EMERGENCIA DEL GÉNERO “RESUMEN EXTENDIDO” BAJO LA ÓPTICA DE LA TEORÍA DE LA COMPLEJIDAD}

RESUMEN: Esta investigación tiene como objetivo relacionar algunas premisas básicas de la Teoría de Complejidad (LARSEN-FREEMAN, 2008; MORIN, 2011) a la noción de géneros textuales - en la perspectiva dialógica del lenguaje de Bakhtin -, identificando, a través de los elementos constitutivos de los géneros - contenido, estilo y construcción composicional -, en qué condiciones el género textual secundario "resumen extendido" emerge en el ámbito académico. Para eso, realizamos una breve discusión acerca de los Géneros Textuales y de la Teoría de Complejidad, discutiendo algunas cuestiones substanciales para la comprensión de esos dos abordajes teóricos como convergentes a partir de la discusión de los siguientes tópicos: los géneros en la visión bakhtiniana; el género textual secundario "resumen extendido"; la emergencia bajo la perspectiva de la complejidad; y la emergencia del género "resumen extendido". En este sentido, entendemos que son las condiciones de uso y la necesidad de cambios que abren espacio para que un género pueda emerger, de modo que, al analizar el género "resumen extendido" bajo la perspectiva de la complejidad, tanto la apertura como la plasticidad de los géneros se vuelven evidentes. Así, percibimos que el trípode constituido por contenido, estilo y construcción composicional evidencia la naturaleza multidimensional y compleja de los géneros textuales, por medio de la relación existente entre esos elementos y la esfera de la comunicación en la que los géneros se anclan.

PALABRAS CLAVE: Complejidad; Género; Resumen extendido.

\section{REFERÊNCIAS}

ANTUNES, Irandé Costa. Encontro do gênero "aviso": da pluralidade à pluralidade. In: ARAÚJO, Antonia Dilamar; LIMA, Paula Lenz Costa (Orgs.). Questões de Linguística Aplicada. Fortaleza: Ed. UECE, 2005.

ARAÚJO, J. C. (org.). Internet \& ensino: novos gêneros, outros desafios. Rio de Janeiro: Lucerna, 2007.

BAKHTIN, Mikhail. Estética da Criação Verbal. 3. ed. São Paulo: Martins Fontes, 2000.

BAKHTIN, Mikhail; VOLOCHÍNOV, Valentin N. Marxismo e filosofia da linguagem. São Paulo: Hucitec, 1987.

BAZERMAN, C. Systems of Genre and the enactment of the social intentions. In.

FREEDMAN, A.; MEDWAY, P. (orgs) Genre and the new rhetoric. London: Taylor \& Francis, 1994, p. 79-101.

BONCKART, J. P. Atividade de linguagem, textos e discursos: Por um interacionismo sóciodiscursivo. São Paulo: EDUC, 1999.

CAIADO, R. V. R. A ortografia no gênero Weblog: entre a escrita digital e a escrita escolar. In. ARAÚJO, J. C. (org.). Internet \& ensino: novos gêneros, outros desafios. Rio de Janeiro:Lucerna, 2007, p. 35-47. 
CASTILHO, Ataliba Teixeira. Análise multissistêmica da sentença matriz. In. PAIVA, Vera Lucia Menezes de Oliveira; NASCIMENTO, Milton do (Orgs.). Sistemas adaptativos complexos: linguagem e aprendizagem. Campinas, SP: Pontes, 2011. p. 35-60.

FARACO, Carlos Alberto. Linguagem \& diálogo: as ideias linguísticas do círculo de Bakhtin. São Paulo: Parábola Editorial, 2009.

HASAN, R. Language, context and text: aspects of language in a social semiotic perspective. Oxford: OUP, 1989.

KUHN, T.S.A estrutura das revoluções cientificas. São Paulo, SP: Ed. Perspectiva, 2003.

LARSEN-FREEMAN, Diane; CAMERON, Lynne. Complex systems and applied linguistics. Oxford: Oxford University, 2008.

LEFFA, Vilson J. Quando menos é mais: a autonomia na aprendizagem de línguas. In: NICOLAIDES, Christine et al (Orgs.). O desenvolvimento da autonomia no ambiente de aprendizagem de línguas estrangeiras. Pelotas: UFPEL, 2003, p. 33-49.

MARTIN, J. R. English texts: Systems and structure. Philadelphia; Amsterdam: john Benjamins Publishing Company,1992.

MEURER, José Luiz; BONINI, Adair; MOTTA-ROTH, Désirée. Gêneros: teorias, métodos, debates. São Paulo: Parábola Editorial, 2005.

MILLER, C. R. Rhetorical Comunity: the cultural basis of genre. In. FREEDMAN, A.; MEDWAY, P. (orgs) Genre and the new rhetoric. London: Taylor \& Francis, 1994; p. 67-78.

MORIN, Edgar. Introdução ao pensamento complexo. 4. ed. Porto Alegre: Sulina, 2011.

MORIN, Edgard; CIURANA, Emilio-Roger; MOTTA, Raúl Domingo. Educar na era planetária: o pensamento complexo como método de aprendizagem no erro e na incerteza humana. Tradução: Sandra Trabucco Valenzuela. São Paulo: Editora Cortez, 2003.

PAIVA, V. L. M. O. E-mail: um novo gênero textual. In: MARCUSHI, L.A.; XAVIER, A. C. S. (orgs) Hipertexto e gêneros digitais: novas formas de construção ao sentido. Rio de Janeiro: Lucerna, 2005, p. 68-90.

PAIVA, Vera Lucia Menezes de Oliveira; NASCIMENTO, Milton do. Sistemas Adaptativos Complexos: linguagem e aprendizagem. Campinas, SP: Pontes, 2011.

RODRIGUES, Rosângela Hammes. Os gêneros do discurso na perspectiva dialógica da linguagem: a abordagem de Bakhtin. In: MEURER, J. L; BONINI, Adair; MOTTAROTH, Désirée. (Orgs.). Gêneros: teorias, métodos, debates. São Paulo: Parábola Editorial, 2005, p. 152-183.

ROJO, Roxane. Gêneros do discurso e gêneros textuais: questões teóricas e aplicadas. In: MEURER, J. L; BONINI, Adair; MOTTA-ROTH, Désirée. (Orgs.). Gêneros: teorias, métodos e debates. São Paulo: Parábola Editorial, 2005, p. 184-207. 
SCHNEUWLY, B; DOLZ J. Gêneros orais e escritos na escola. Campinas, SP: Mercado das Letras, 2004.

SWALES, J. M. Genre Analysis. English in academic and research settings. Cambridge: Cambridge University Press, 1990.

XAVIER, A. C.; SANTOS C. F. E-forum na Internet: um gênero digital. In: ARAÚJO, J. C; BIASI-RODRIGUES B. (org) Interação na internet: novas formas de usar a linguagem. Rio de Janeiro: Lucerna, 2005, p. 30-38.

Recebido em: 19/05/2019. Aprovado em: 19/08/2019. 